\title{
Parkinsonism induced by a monoamine oxidase inhibitor
}

\author{
M.A. Gillman and R. Sandyk \\ South African Brain Research Institute, Suite 9, Highlands House, 173 Louis Botha Avenue, Orange Grove, 2192, \\ Johannesburg, South Africa
}

\begin{abstract}
Summary: A parkinsonian syndrome developed 5 weeks after administration of phenelzine in a 42 year old woman with major depressive illness. Discontinuation of this agent resulted in gradual disappearance of the extrapyramidal syndrome. Possible underlying mechanisms for this unusual case are discussed.
\end{abstract}

\section{Introduction}

Monoamine oxidase inhibitor (MAOI) agents have been increasingly used in the past for the treatment of patients with 'atypical' depression and phobic states (Robinson et al., 1978). Administration of these agents is associated with increased concentrations of serotonin, noradrenaline and dopamine in the central nervous system (Shaw et al., 1982). Recently, a selective inhibitor of monoamine oxidase B (MAO-B) (deprenyl) has been introduced and found effective in the management of Parkinson's disease (Birkmayer $e t$ al., 1975; Lees et al., 1977).

Central nervous system side effects of the MAOI drugs include drowsiness, blurred vision and headaches. At toxic dosages, they may cause euphoria, agitation, hallucinations and hypertensive crisis (Robinson et al., 1978).

We report a patient in whom administration of the MAOI agent phenelzine $\left(\mathrm{Nardil}^{\mathrm{R}}\right)$ resulted in the development of a parkinsonian syndrome that remitted after the drug was discontinued.

\section{Case report}

A 42 year old woman who met DSM-III criteria of major depressive disorder received phenelzine after being unresponsive to treatment with conventional tricyclic antidepressants, lithium carbonate and electro-convulsive therapy. There was no history of alcohol abuse. All medication was discontinued 2 weeks before administration of phenelzine. The latter was given initially at a dosage of $15 \mathrm{mg}$ twice daily for a period of 2 weeks and resulted in some improvement of the patient's mood and anxiety state. Thereafter the dosage was raised to $30 \mathrm{mg}$ twice daily with further

Correspondence: R. Sandyk, M.D.

Accepted: 4 July 1985 improvement in the patient's mental state, over the following 3 weeks.

Mild frontal headache was the only side effect recorded during the initial 5 weeks of therapy. Approximately 5 weeks after initiation of treatment she noticed generalized slowing of movement, the presence of bilateral tremor in both hands and jaw and difficulties in speech. Examination revealed bradykinesia, amimia, stooped posture and slow monotonous speech. There was cogwheel rigidity in both wrists and neck muscles. Glabellar tap was positive. Tendon jerks were hypoactive and plantar responses flexor. Examination of the cranial nerves and eye-grounds was normal. There was no sensory deficit and micturition was unimpaired. Blood pressure was $150 / 100 \mathrm{~mm} \mathrm{Hg}$, pulse 80 beats $/ \mathrm{min}$. There was no evidence for postural hypotension. Computed tomographic (CT) scan of the brain with contrast administration was normal. Urine lithium and neuroleptic screening was normal. Because of possible extrapyramidal side effects of phenelzine, the latter was gradually discontinued over a period of 2 weeks with the result that the parkinsonian picture gradually abated, completely resolving within 10 days of the withdrawal of medication. She was then put onto maprotiline plus propranolol. She gradually became more depressed and anxious and necessitated hospitalization in a psychiatric nursing home.

\section{Discussion}

Apart from neuroleptic and alcohol-induced Parkinson's disease, one cannot exclude the possibility that this patient presented with idiopathic parkinsonism. This, however, seems unlikely, since follow-up of the patient over a further year showed no evidence of the disease. In addition our case differs from that described by Teusink et al. (1984) in a number of ways.

The Fellowship of Postgraduate Medicine, 1986 
First our patient was relatively young whilst their patient was 75 . Second, our patient had no initial signs of neurological dysfunction, whilst the older patient showed mild right sided hyperreflexia, right extensor plantar reflex plus positive suck and snout reflexes prior to phenelzine administration. Furthermore, the latter patient had received a higher dose of phenelzine $(75 \mathrm{mg} /$ day) before the onset of parkinsonian symptoms than our patient.

The underlying mechanism that precipitated this case can only be speculated upon, particularly as MAOI agents block the degradation of dopamine (Shaw et al., 1982) and would therefore be expected to be therapeutic.

Indeed the MAOI deprenyl (which preferentially inhibits MAO-B) has been shown to improve the symptoms of Parkinson's disease by its selective effect of increasing dopamine within the synaptic cleft (Reiderer \& Reinolds, 1980). However, phenelzine is

\section{References}

BIRKMAYER, W., RIEDERER, P., YOUDIM, M.B.H. \& LINAUER, W. (1975). The potentiation of anti akinetic effect after L-Dopa treatment by an inhibitor of MAO-B, Deprenil. Journal of Neural Transmission, 36, 303.

HO, A.K.S., SINGER, G. \& GERSHON, S. (1971). Biochemical evidence of adrenergic interaction with cholinergic function in the central nervous system of the rat. 1: effect of norepinephrine. Psychopharmacologia, 21, 238.

LEES, A.J., KOHOUT, L.J., SHAW, K.M., STERN, G.M., ELSWORTH, J.D., SANDLER, M. \& YOUDIM, M.B.H. (1977). Deprenyl in Parkinson's disease. Lancet, ii, 791.

PYCOCK, C.J. \& KRUK, Z.L. (1979). In Neurotransmitters and Drugs. Croom Helm: London.

RIEDERER, P. \& REINOLDS, G.P. (1980). Deprenyl is a selective inhibitor of brain MAO-B in the long-term treatment of Parkinson's disease. British Journal of Clinical Pharmacology, 9, 88. less selective and seems to inhibit both MAO-A and MAO-B with similar efficacy (Pycock \& Kruk, 1979). This would lead to increases of both serotonin and noradrenaline as well as dopamine within synapses (Pycock \& Kruk, 1979).

Since raised levels of noradrenaline can cause increased levels of acetylcholine, this could lead to a relative inbalance between the dopamine and acetylcholine systems which could lead to parkinsonism (Teusink et al., 1984). Furthermore, increased serotinergic activity can cause inhibition of striatal dopaminergic neurones (Waldmeier \& Delini-Stula, 1979).

Alternatively, one could suggest the possibility that administration of phenelzine resulted in accumulation of dopamine in the synaptic cleft with resultant postsynaptic subsensitivity of dopamine receptors. It is possible that such 'down-regulation' could lead to a net deficit of dopamine in the striatum.

ROBINSON, D., NIES, A., RAVARIS, C.L., IVES, J.O. \& BARTLETT, D. (1978). Clinical pharmacology of phenelzine. Archives of General Psychiatry, 35, 629.

SHAW, D.M., KELLAM, A.M.P. \& MOTTRAM, R.F. (1982). In Brain Sciences in Psychiatry. pp. 157-213. Butterworths London.

TEUSINK J.P., ALEXOPOULOS, G.S. \& SHAMOIAN, C.A (1984). Parkinsonian side effects induced by a monoamine oxidase inhibitor. American Journal of Psychiatry, 141; 118.

WALDMEIER, P.C. \& DELINI-STULA, A.A. (1979). Serotonindopamine interactions with cholinergic function in the nigro-striatal system. European Journal of Pharmacology, 55, 363. 